Saber Humano, ISSN 2446-6298, V. 7, n. 11, p. 296-312, jan./jun. 2017.

\title{
MOTIVAÇÃO NA ADMINISTRAÇÃO PÚBLICA: UM ESTUDO DE CASO EM UMA UNIDADE DA POLÍCIA RODOVIÁRIA FEDERAL
}

\author{
Jéssica Inácio de Lima ${ }^{1}$ \\ Lucas Charão Brito ${ }^{2}$ \\ Sandra Leonara Obregon ${ }^{3}$ \\ Luciana Raquel Nunes Irineu Moura ${ }^{4}$ \\ Luis Felipe Dias Lopes ${ }^{5}$ \\ Fábio Teodoro Tolfo Ribas ${ }^{6}$
}

\begin{abstract}
Resumo
O estudo tem por objetivo identificar os fatores que mais motivam os Policiais Rodoviários Federais. Metodologicamente, caracteriza-se por ser um estudo de caso com abordagem qualitativa, sendo utilizado como instrumento de coleta de dados um entrevista em profundidade realizada em uma amostra composta de 11 policiais de uma unidade da PRF pertencente à $9^{\mathrm{a}}$ Superintendência ( $\left.9^{\mathrm{a}} \mathrm{SRPRF} / \mathrm{RS}\right)$. Quanto à técnica de análise de dados, esta foi feita por meio da análise de conteúdo. Os resultados apontaram que os fatores que mais os motivam são: relacionamento entre colegas e remuneração, aliados a estabilidade e a escala de serviço. Contudo, há fatores que contribuem para a desmotivação dos profissionais, como: promessas não cumpridas, desvalorização e suspensão de benefícios.
\end{abstract}

Palavras-chave: Policiais Rodoviários Federais. Administração Pública. Motivação.

\section{MOTIVATION IN PUBLIC ADMINISTRATION:}

A CASE STUDY IN A POLICE UNIT ROAD FEDERAL

\begin{abstract}
The study aims to identify the factors that motivate the Federal Highway Patrol. Methodologically, it is characterized as a case study with a qualitative approach, being used as an instrument of data collection an in-depth interview conducted in a sample composed of 11 police officers from a unit of the PRF belonging to the 9th Superintendence (9th SRPRF / RS) . As for the technique of data analysis, this was done through content analysis. The results indicated that the factors that motivate them most are: peer relationships and compensation, allied to stability and service schedule. However, there are factors that contribute to the demotivation of professionals, such
\end{abstract}

\footnotetext{
${ }^{1}$ Graduada em Administração - FSG;

${ }^{2}$ Graduado em Administração - FDA; Doutorando em Administração - UFSM;

${ }^{3}$ Graduada em Administração - UNIFRA; Doutoranda em Administração - UFSM;

${ }^{4}$ Graduada em Administração - CUA; Mestranda em Administração - UFSM;

5 em Matemática - FIC; Professor Associado do Depto. De Ciências Administrativas - UFSM;

${ }^{6}$ Graduado em Administração; Mestre em Administração - UFSM; Professor da FSG
} 
Saber Humano, ISSN 2446-6298, V. 7, n. 11, p. 296-312, jan./jun. 2017.

as: unfulfilled promises, devaluation and suspension of benefits.

Keywords: Federal Highway Patrol. Public Administration. Motivation.

\section{Resumen}

El estudio tiene por objetivo identificar los factores que más motivan a los Policías Rodoviarios Federales. En el presente trabajo se analizan los resultados obtenidos en el análisis de los resultados obtenidos en el análisis de los resultados obtenidos en el estudio, . En cuanto a la técnica de análisis de datos, ésta fue hecha por medio del análisis de contenido. Los resultados apuntaron que los factores que más los motivan son: relación entre colegas y remuneración, aliados a la estabilidad y la escala de servicio. Sin embargo, hay factores que contribuyen a la desmotivación de los profesionales, como: promesas incumplidas, devaluación y suspensión de beneficios.

Palabras clave: Policías Rodoviarios Federales. Administración publica. Motivación.

\section{INTRODUÇÃO}

Vive-se em um mundo que está sofrendo grandes transformações e, essas transformações estão por toda a parte, sejam de ordem política, econômica ou social. A responsável por essas mudanças é a globalização. Sua contribuição está ligada principalmente no que tange às relações sociais, ou seja, modificou-se a forma de interação entre as pessoas e consequentemente mudaram também as organizações, isto é, estas estão voltadas para uma visão humanística, buscando a qualidade de vida de seus funcionários, bem como um bom ambiente de trabalho em que se sintam motivados, para assim apresentar bons resultados para a organização. Esse novo comportamento organizacional é devido às pessoas deterem muitas informações, assim é possível comparar o que cada organização tem de positivo, dessa forma não se sujeitam a trabalhar em qualquer lugar.

Sob esta ótica, o presente estudo aborda uma questão muito importante na Gestão de Pessoas: a motivação. Seu enfoque é na administração pública e mais precisamente na Polícia Rodoviária Federal, em uma unidade pertencente à $9^{\mathrm{a}}$ Superintendência da Polícia Rodoviária Federal (SRPRF), situada no Estado do Rio Grande do Sul. A relevância deste estudo se justifica pela importância que a motivação exerce nas pessoas, em razão de que é por meio dela que é possível compreender o comportamento do indivíduo.

Vergara (1999) define motivação como sendo uma energia que impulsiona as 
pessoas na direção para atingir algo, essa impulsão é natural, ou seja, vem das necessidades interiores de cada indivíduo e está presente em todos os lugares onde se encontram pessoas motivadas e pessoas que necessitam dela. No entanto, cientificamente, o tema é abordado com menos frequência na administração pública, mas é de grande relevância debater esse assunto principalmente na esfera geral, uma vez que a máquina pública é gerida por pessoas e estas, por sua vez, também possuem expectativas, anseios, sentimentos, entre outros.

É consenso que no setor privado é um desafio motivar pessoas, porém, pode-se afirmar que, na administração pública, o desafio é bem maior, porque o sistema de funcionamento é totalmente diferente do privado. A forma de recrutamento é por meio de concurso público, portanto a maioria das ações depende de instrumentos legais, como leis, decretos, portarias, etc., mas isso não extingue as necessidades dos servidores como: reconhecimento, valorização, sentimento de utilidade, ou seja, tais necessidades são presumidas por se tratar de pessoas e não de máquinas que podem ser programadas a qualquer tempo.

Diante da situação apresentada, limita-se o tema deste estudo à motivação dos Policiais Rodoviários Federais, sendo assim, o objetivo geral é analisar os fatores motivacionais presentes na carreira dos policias rodoviários federais, tendo como objetivos específicos: levantar o perfil do policial rodoviário federal; identificar os elementos que influenciam na sua motivação e verificar se há alguma prática de Gestão de Pessoas por parte da Administração Pública que interfira no aspecto motivacional dos servidores (policiais).

\section{FUNDAMENTAÇÃO TEÓRICA}

Este capítulo abordará uma breve temática relativa às características que envolvem a administração pública, como princípios constitucionais e estatuto dos servidores públicos da União. Da mesma maneira, irá abordar aspectos que envolvem a motivação, tais como: comportamento organizacional, conceitos de motivação e principais teorias motivacionais e, por fim, a motivação na Administração Pública.

\subsection{Princípios Constitucionais da Administração Pública}


No setor privado há as Diretrizes Organizacionais (missão, visão, valores e objetivos), que são elementos que a organização segue visando à realização dos objetivos. Na administração pública, existem Princípios Constitucionais que norteiam todo o sistema na esfera Federal, Estadual e Municipal. Os princípios estão mencionados no artigo 37, caput $^{1}$, da Constituição Federal de 1988 (C.F/88) sendo estes: legalidade, impessoalidade, moralidade, publicidade e eficiência. Cabe ressaltar que os princípios citados são meramente exemplificativos, podendo cada estado ou município acrescentar.

\subsection{Regime Estatutário dos Servidores da União (Lei 8.1120/90)}

A lei no 8.112 /90 "é o regime jurídico dos servidores ocupantes de cargos públicos e cargos em comissão da União, bem como suas pessoas jurídicas de direito público: autarquias, fundações públicas, agências reguladoras e associações públicas federais" (MAZZA, 2013, p.498). Nesse estatuto, estão descritos todos os momentos da trajetória de um servidor público federal, tais como: concurso, aprovação, provimento, posse, exercício, estágio probatório, confirmação, estabilidade, saída do cargo.

Grande parte do que contém este estatuto aplica-se à PRF, e um dos motivos que mais motivam as pessoas a ingressarem na carreira pública, inclusive, é a estabilidade, uma vantagem adquirida após o estágio probatório. O estágio probatório é um período de avaliação durante o qual o servidor deverá demostrar aptidão e capacidade para o exercício do cargo, observado os fatores: assiduidade, disciplina, capacidade de iniciativa, produtividade e responsabilidade, Art. 20 da Lei nº8112/90.

\subsection{Conceitos de Motivação}

A palavra motivação vem do latim moveres (mover) que significa mover para algo, ou seja, um impulso interno (psicológico) que resulta a ação, isto é, dependendo do impulso induz uma pessoa a assumir determinados comportamentos (MAXIMIANO, 2006). Lorenz (1995) argumenta que o ser humano possui um estado de carência que o mesmo tenta suprir. Satisfeita essa necessidade, o indivíduo cria outras para supri-las.

Robbins (2005, p.132) também nesse sentido define motivação como sendo “o 
processo responsável pela intensidade, direção e persistência dos esforços de uma pessoa para alcance de uma determinada meta". Seguindo o raciocínio de Robbins (2008), observa-se na Figura 1, o ciclo de criação da motivação.

Figura 1 - Esquema do processo de motivação.

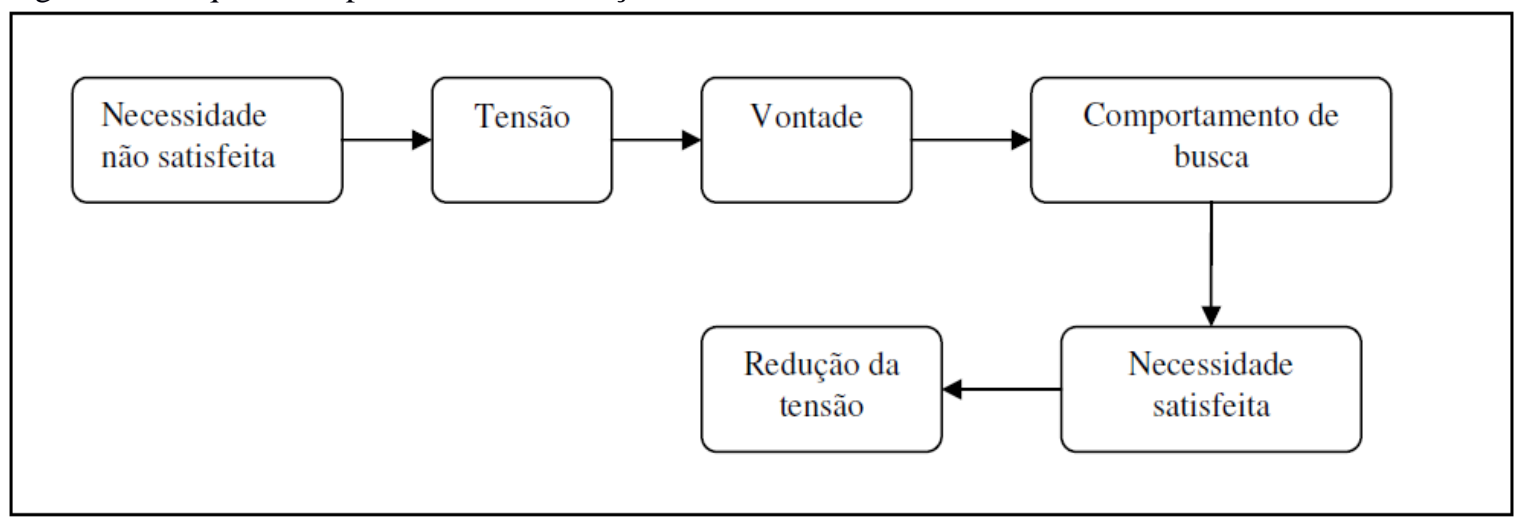

Fonte: Robbins (2008, p.46).

Ao analisar a figura de Robbins (2008), é possível identificar que uma necessidade não satisfeita gera uma tensão, despertando a vontade da pessoa. Em consequência disso, ou seja, da vontade, é possível buscar objetivos e metas e, quando satisfeitas, resulta em necessidade satisfeita diminuindo, assim, a tensão. Com essa explanação, pode-se dizer que a motivação é momentânea e que sempre necessita de novos desafios para dessa forma gerar o processo de busca da satisfação de uma necessidade.

Porém, outros autores defendem o contrário, afirmando que a motivação não está apenas ligada às necessidades individuais e sim que ela pode ser alcançada por meio do ambiente, bem como das pessoas que compõem o grupo. Em razão disso, os gestores devem estar sempre atentos como está a motivação de seus funcionários, e é dever dos mesmos procurar conhecer as necessidades de sua equipe, assim como, verificar se a organização está sendo competente para satisfazê-las (VIANNA, 1997).

$\mathrm{Na}$ literatura encontram-se essas principais posições, todavia, é possível encontrar um equilíbrio perante cada posicionamento. $\mathrm{O}$ ambiente e as pessoas são capazes de motivar terceiros de forma positiva, entretanto, a pessoa tem que querer (decisão individual). Salgado (2005, p.20) alude essa questão definindo que “motivação é a disposição de exercer um nível elevado e permanente de esforço, em favor das metas da empresa, sob a condição de que o esforço seja capaz de satisfazer alguma necessidade individual”. 


\section{4 Principais teorias motivacionais}

Estudos iniciais sobre motivação tiveram um grande papel para a humanidade, dado que graças a esses estudos, atualmente é possível entender o comportamento humano oportunizando uma maior compreensão sobre as pessoas e ambiente de trabalho. A teoria da Hierarquia das Necessidades, proposta por Abram Maslow em 1943 foi a pioneira sobre motivação e até os dias atuais é debatida. Essa teoria estabelece que todo o ser humano apresenta uma hierarquia de necessidades. No total são cinco, sendo que as três primeiras são necessidades de carência, significando que são essenciais para a sobrevivência do indivíduo no habitat. Já as duas restantes são necessidades de crescimento, pois estão diretamente relacionadas com a realização de cada pessoa (SALGADO, 2005).

Outra teoria bastante conhecida é a de Frederick Herzberg, que divide em dois grupos os fatores que afetam o comportamento do indivíduo: os higiênicos e os motivacionais, denominando-se a Teoria dos Dois Fatores de Herzberg. Os fatores Higiênicos estão relacionados ao ambiente externo do indivíduo, que compreende benefícios, salários, segurança e relações (FIORELLI, 2003). Já os fatores motivacionais estão relacionados com o trabalho em si, ou seja, os resultados do trabalho, como: reconhecimento, crescimento, responsabilidades exercidas, realização, etc (KRUMM, 2005). O autor concluiu ainda que, os "fatores intrínsecos estão relacionados à satisfação no trabalho, ao passo que os extrínsecos estão associados à insatisfação", assegurando (SALGADO 2005, p. 24).

Em 1957 Douglas McGregor desenvolveu a chamada Teoria X e Teoria Y. Essa teoria propõe duas visões distintas do ser humano, ou seja, um lado positivo (Teoria X) e outro negativo (Teoria Y). A Teoria $\mathrm{X}$ allude a uma visão mais tradicional do indivíduo, afirmando que o ser humano não gosta de trabalhar e que por isso precisa ser ameaçado de ser punido para assim atingir os objetivos organizacionais. Já a Teoria Y, indica um cenário contrário: as pessoas integram-se com os objetivos organizacionais e têm disposição de forma natural para trabalhar. A punição e ameaça não são os únicos meios para estimular o trabalho, associar as pessoas com os objetivos organizacionais assegurando que os resultados de todos contribuem para o sucesso dos objetivos e que todos poderão ser beneficiados com isso, pode ser outra forma de estímulo para um bom 
ambiente de trabalho, afirma (FALLER, 2004).

Por fim, a última teoria a ser apresentada, é atribuída a John Stacy Adams (1963), a Teoria da Equidade. A própria denominação já remete ao seu significado, ou seja, a igualdade. Os funcionários estão a todo momento comparando as suas entradas (esforço, competências, experiências) e resultados (remuneração, reconhecimento) com os outros funcionários e, quando essas relações são iguais, afirma-se que há equidade, isto é, justiça. Porém, quando ocorre o contrário, a inequidade, em uma situação tal que a injustiça está presente, isso gera um estado de tensão negativo, que poderá motivar para que uma ação corretiva seja tomada a fim de buscar a justiça, conclui (ROBBINS, 2005).

\subsubsection{Motivação na Administração Pública}

No setor público o tema foi discutido recentemente, Santana (2011, p.31) explica que:

\footnotetext{
O tema motivação é uma novidade na administração pública e os trabalhos que se referem ao mesmo são bem diversos uns dos outros, abordando áreas distintas $[\ldots]$ há autores que concluem que há oportunidades para novos estudos na administração pública envolvendo gestão de pessoas e relações de trabalho.
}

No entendimento de Santana (2011), muitas pessoas veem os servidores públicos como pessoas acomodadas, descomprometidas e sem motivação para trabalhar, contudo, isso não pode tornar-se regra, visto que nem todas as pessoas possuem o mesmo perfil, independentemente se trabalha ou não na administração pública. E ainda ressalta que, o comportamento humano possui uma motivação que é originada de cada indivíduo.

Bergue (2007) destaca na Figura 2 alguns incentivos atrativos que levam as pessoas a ingressarem na carreira pública. Todavia, isso pode ter efeito contrário se a administração pública não impor desafios e inovar, visto que as pessoas acostumam-se facilmente com esses elementos. 
Figura 2 - Componentes do sistema de incentivos

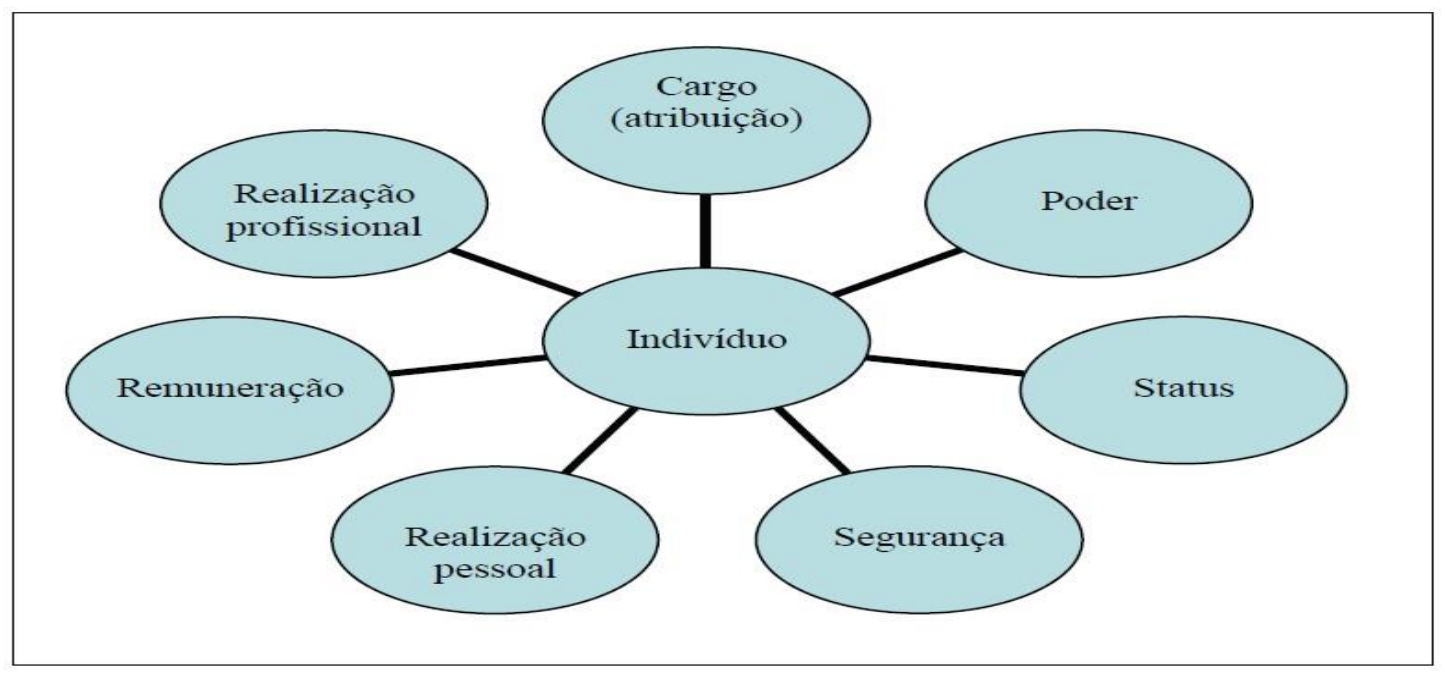

Fonte: Bergue (2007, p.255)

Bergue (2007) finaliza seu entendimento afirmando que a estabilidade é o que mais caracteriza os cargos públicos, e não isoladamente a remuneração, ou status conferido pelo exercício do cargo e poder, partes integrantes do conjunto atributivo dos cargos públicos. Entretanto, a administração pública tem que cobrar a contrapartida dessas características, ou seja, todas as habilidades e competências desenvolvidas durante a carreira do servidor devem resultar em qualidade nos serviços oferecidos, bem como servir de ferramenta para a valorização profissional das pessoas em relação ao trabalho.

\section{METODOLOGIA}

Para atingir o objetivo proposto, que foi analisar os fatores motivacionais presentes na carreira dos Policias Rodoviários Federais, o tipo de pesquisa adotada foi a descritiva, que segundo Cervo, Bervian e Da Silva (2012, p.61) "observa, registra, analisa e correlaciona fatos ou fenômenos sem manipulá-los. Procura descobrir com a maior precisão possível a frequência que um fenômeno ocorre, sua relação e conexão com os outros, sua natureza e características". A abordagem desse estudo foi de cunho qualitativo e, conforme Marconi; Lakatos (2008, p. 136), "baseados na presença ou na ausência de alguma qualidade ou característica e também na classificação de tipos diferentes de cada propriedade".

O procedimento adotado foi o estudo de caso, que tem como objetivo explicar, 
descrever ou explorar determinada situação da vida real. Cervo, Bervian e Da Silva (2012, p. 62) definem estudo de caso como sendo uma "pesquisa sobre um determinado indivíduo, família, grupo ou comunidade que seja representativo de seu universo para examinar aspectos variados de sua vida". Analisou-se apenas uma unidade da PRF, não podendo esse estudo ser comparado com as demais unidades existentes da PRF.

\subsection{Delimitação da população e amostragem}

A população de Policias Rodoviários Federais totaliza em dez mil policiais. Contudo, nesse estudo foram investigados servidores que exercem suas atividades em uma unidade da PRF localizada na BR 290, pertencente à 9a Superintendência de Polícia Rodoviária Federal ( $\left.9^{\circ} \mathrm{SRPRF} / \mathrm{RS}\right)$, com uma amostra de 11 policiais. A localidade específica da unidade não será divulgada por motivos de regulamentação interna. Por tratar-se de um número pequeno em relação aos policiais existentes no Brasil, foi uma amostragem não probabilística, que necessariamente não possui o objetivo de representar estatisticamente a população alvo. Consequentemente, o pesquisador usa métodos subjetivos, como por exemplo, a própria experiência pessoal para selecionar os elementos da amostra.

Seguindo o raciocínio de JR. et al (2007), o método de amostragem não probabilístico adequado para este estudo é o de Amostragem por Julgamento. Essa modalidade permite que o julgamento do pesquisador seja usado para selecionar os elementos da amostra, pois o investigador acredita que eles representam a população alvo, não necessariamente representativo.

\subsection{Técnica de coleta de dados}

Os dados foram coletados por meio de entrevista, realizando-se uma entrevista em profundidade, semiestruturada que constitui-se em uma discussão individual entre entrevistador e entrevistado. A entrevista em profundidade oferece uma sondagem mais detalhada, além do entrevistado ficar mais à vontade para discutir tópicos delicados (JR., et al, 2007). Outro método de coleta de dados utilizado foi a observação não participante, desta forma a situação investigada oferece mais confiança na coleta dos dados. Para melhor entendimento, Barros e Lehfeld (2007, p.75) conceituam que essa 
técnica "é um tipo de observação em que o observador permanece fora da realidade a estudar. A observação é feita sem que haja interferência ou envolvimento do observador na situação. O pesquisador tem o papel de espectador".

A fim de obter maior qualidade dos dados coletados, complementou-se a coleta com dados secundários. De acordo com Malhotra (2010, p. 80) "são dados que foram coletados para objetivos que não os problemas em pauta e podem ser localizados de forma rápida e barata". Isto é, dados coletados por órgãos governamentais que estão disponíveis para consulta.

\subsection{Técnica de análise de dados}

Para analisar os dados coletados, utilizou-se a análise de conteúdo que visa obter dados por meio da observação. Essa técnica permite analisar conteúdo de diversas fontes como: livros, revistas, jornais, discursos, propaganda de rádio e televisão, slogan, etc, bem como se destina aos produtos da ação humana voltada para o estudo das ideias e não da palavra em si (MARCONI; LAKATOS, 2008). A análise do conteúdo é conveniente para esse estudo porque as perguntas são abertas e concede ao pesquisador obter outros dados.

\section{ANÁLISE DE DADOS}

Este capítulo apresenta os dados obtidos por meio da entrevista em profundidade e observação não participante em uma unidade pertencente à $9^{\text {a }}$ Superintendência da Policia Rodoviária Federal (SRPRF). Tais resultados propõem conhecer quais os fatores motivacionais presentes na carreira de um Policial Rodoviário Federal, bem como entender quais os aspectos motivacionais que mais influenciam em suas carreiras.

\subsection{Perfil da amostra}

Num primeiro momento, identificou-se o perfil predominante da amostra, composta por 11 indivíduos, sendo que todos possuem o cargo de Policial Rodoviário Federal, ou seja, todos fazem parte do operacional da PRF. Vale ressaltar que apenas um policial acumula funções, isto é, além de executar sua função no operacional é o elo 
de comunicação entre a delegacia e o posto da PRF, essa função denomina-se policial adjunto.

No que diz respeito ao gênero, 10 dos 11 entrevistados são do gênero masculino (90,9\%), ou seja, verifica-se que é um ambiente predominantemente masculino. Quando questionados sobre o tempo de serviço, obteve-se que sete entrevistados têm nove anos de serviço, isso corresponde a $64 \%$ do total de entrevistados; dois entrevistados (18\%) têm 10 anos de serviço e os dois restantes são o maior e o menor tempo de cargo, ou seja, o policial que tem menor tempo de serviço é de um ano e meio, e o que possui mais tempo é um policial que tem 18 anos de exercício na carreira.

Em relação à escolaridade, $82 \%$ dos entrevistados têm ensino superior completo, isso equivale a nove entrevistados. Os dois entrevistados restantes possuem ensino superior incompleto e ensino médio completo respectivamente. A média da renda familiar obtida foi de $\mathrm{R} \$ 11.318,00$. A média de idade foi de 37 anos, sendo que o mais novo policial tem 30 anos e o mais velho 49 anos de idade. A seguir, serão expostos os resultados relativos às entrevistas em profundidade.

\subsection{Fatores motivacionais na carreira do Policial Rodoviário Federal}

De maneira predominante, oito entrevistados apontaram que um dos principais motivos que os levaram a ingressar na carreira de Policial Rodoviário Federal foi a remuneração. A atração pela remuneração é comprovada pelo nono entrevistado que afirmou: "não era um sonho e sim por necessidade", o terceiro também deixou claro a sua necessidade, dizendo que "[...] eu precisava trabalhar, sair de casa". A remuneração é um fator associado à Pirâmide de Maslow (1943) adaptada por Chiavenato (2010), aplicado à necessidade de segurança pelo fato de propiciar um bom poder aquisitivo, atendendo suas necessidades imediatas.

A estabilidade, outro ponto citado por cinco entrevistados, também vincula-se à necessidade de segurança, em razão de ser uma forma de permanência no cargo, ou seja, é uma garantia de um futuro seguro.

Em relação à escala de serviço, quatro foram os entrevistados que responderam como um motivo para o ingresso na carreira. O fato de ser flexível os possibilita realizar várias atividades, como dedicar tempo à família, aos estudos, etc., ou seja, possibilita uma boa qualidade de vida. Seguindo o raciocínio de Chiavenato (2010), a 
escala de serviço com que muitos entrevistados simpatizam associa-se às necessidades fisiológicas, uma vez que permite o descanso físico por meio de seus intervalos flexíveis.

Outro aspecto questionado é se o relacionamento interpessoal interfere de alguma forma na motivação, então seis sustentam que o relacionamento interfere na motivação, principalmente entre colegas do mesmo nível de atividade, e o terceiro entrevistado admitiu que o relacionamento não tem grandes impactos na sua motivação. É importante acentuar a fala do quarto entrevistado: “o relacionamento é bom, mas às vezes há alguns atritos, acredito que seja em função muitas vezes do gênero”. Esse fato ocorre, pois essa entrevistada é a única mulher na unidade em estudo. Notou-se que as respostas dos entrevistados remetem à Teoria da Equidade de Adams (1963), que é a comparação constante entre os funcionários com o intuito de verificar se a justiça prevalece no ambiente, ou seja, se há igualdade entre eles (ROBBINS, 2005).

Quando perguntados sobre as vantagens pecuniárias que esses servidores percebem e se as consideram motivacionais, sete entrevistados responderam que sim, inclusive o oitavo entrevistado disse "trabalho para ganhar dinheiro", enfatizando o quão as vantagens pecuniárias para ele são importantes. Contudo, o sexto entrevistado afirmou que "é motivacional em partes, a gente se acostuma rápido e deixa de ser tão motivacional”.

No que diz respeito às vantagens não pecuniárias, por unanimidade, os 11 entrevistados acreditam que essas são motivadoras. Mas, somente se forem unidas às pecuniárias, isto é, as vantagens não pecuniárias isoladas não são tão motivadoras, fator apontado por seis entrevistados.

No tocante à motivação que a estrutura impacta, três entrevistados afirmaram que a estrutura afeta na motivação para o trabalho e, desses, o sétimo entrevistado especificou essa questão, assegurando que a estrutura afeta na execução das atividades. O relato do segundo entrevistado confirma "olha, eu acho boa, perto de lá pra cima sei que é bem pior". Por outro lado, o terceiro entrevistado considera o contrário: "pra mim a estrutura não afeta em nada na minha motivação”.

Quando questionados sobre as práticas de Gestão de Pessoas da Coordenação Geral de Recursos Humanos (CGRH) ou da Seção de Recursos Humanos (SRH), relevantes para a sua motivação, quatro entrevistados afirmaram que não possuem 
conhecimento de nenhuma prática de Gestão de Pessoas, visto que o RH flutua muito, ou seja, depende muito da pessoa que está no comando e não há padrões, e nem as pessoas que ocupam essas funções são formadas na área de gestão.

Questionados sobre as suas percepções sobre a motivação na carreira, quatro entrevistados disseram que a percepção é boa e que estão motivados, apesar de as vantagens pecuniárias estarem sendo cada vez mais tolhidas pela inflação ou mesmo sofrendo alguns cortes. Já seis entrevistados consideram que a sua motivação está muito baixa, e percebe-se essa desmotivação com a fala do décimo entrevistado: " $a$ minha tá horrível, já quero ir para outro concurso [...]”."

São vários os fatores que se somam para chegar à desmotivação, são muitas promessas feitas que aguçam a expectativa, gerando um sentimento de desvalorização quando ela não é atingida plenamente, questão destacada pelo sexto entrevistado. Há carreiras que, há alguns anos, recebiam bem menos proventos que a carreira de policial rodoviário federal e, hoje o inicial destas é o salário de um policial em final de carreira, questão levantada pelo $11^{\circ}$ entrevistado. Justamente esses fatores estão desmotivando dois entrevistados que não querem se aposentar nessa carreira, ou seja, querem migrar para outras carreiras que julgam ser mais valorizadas. A saída da carreira não é algo novo para os servidores da unidade, há pouco tempo dois servidores haviam pedido exoneração pois passaram em outros concursos.

Observa-se que mais da metade dos efetivos, isto é, seis entrevistados afirmaram que sua motivação está muito baixa, pior do que quando entraram. Segundo a Teoria dos Dois Fatores de Herzberg, há dois fatores que afetam o comportamento do indivíduo, os higiênicos (desagradam) e motivacionais (agradam). Os altos índices de insatisfação surgem com a falta dos fatores higiênicos, isto é, condições de trabalho, salário, segurança, etc., (FIORELLI, 2003). De fato, com os relatos, verificou-se que a insatisfação está diretamente relacionada às promessas não cumpridas, à falta de estrutura e à falta de valorização do trabalho

Ainda em relação à desmotivação, o sentimento de abandono foi mencionado por dois entrevistados, inclusive o sétimo entrevistado declarou que "eu já levei um tiro em serviço e ninguém me ligou para saber se tava vivo [...] descaso total". $O$ PROSERV, que é o Programa de Saúde do Servidor, foi citado por dois entrevistados, porém não atuante como uma forma preventiva em relação ao estresse ou pressão.

No que tange às práticas de gestão de pessoas da CGRH e SRH, comprovou-se 
que as práticas de prevenção de estresse e pressão são muito deficientes, não há nenhuma ação. Quanto à comunicação, pode-se afirmar que ela é razoavelmente boa e que já melhorou muitas situações com a inclusão de novas vias de comunicação, apesar disso o acesso à informação é satisfatório na esfera operacional, não tendo o mesmo resultado na área administrativa.

Prosseguindo, no que alude aos fatores motivacionais que os entrevistados consideram prioritários no ambiente de trabalho, obtiveram-se diversas respostas. De forma predominante, sete citaram o relacionamento, isto é, consideram prioritários no ambiente de trabalho o coleguismo, já que as atividades são sempre realizadas em conjunto. Outro ponto citado por quatro entrevistados foram as vantagens pecuniárias, uma vez que essas vantagens ainda têm a sua atração e, como levantado pelo sétimo entrevistado, "é preciso trabalhar para sobreviver, é isso que me move". A escala de serviço também foi relacionada como um dos fatores motivacionais, já que possui flexibilidade e agrada a maioria dos servidores que não residem na cidade da unidade em estudo, este fator foi indicado por três entrevistados.

Reconhecimento foi outro fator mencionado por três entrevistados, eles acreditam que, se fossem reconhecidos como deveriam ser, isso alavancaria a motivação. Porém, segundo esses entrevistados, o descaso, as promessas não cumpridas e os cortes de benefícios só fazem com que eles sintam-se desvalorizados. O primeiro entrevistado completa afirmando que "o reconhecimento não deve partir somente da chefia ou da administração pública [...] deve partir também dos colegas".

Diante tudo o que foi exposto, por meio de todos os questionamentos, constatou-se que ainda é a remuneração o fator que mais atrai o policial para o ingresso na carreira, porém não isoladamente, pois é necessário unir este a outros fatores para assim proporcionar uma boa qualidade de vida, alguns exemplos são a escala e a estabilidade.

No que concerne à percepção sobre a motivação na carreira, predominou que mais da metade dos entrevistados estão com sua motivação muito baixa, sendo necessárias medidas para melhorar esse cenário.

\section{CONSIDERAÇÕES FINAIS}

Tendo em vista que o objetivo geral deste estudo foi analisar os fatores 
motivacionais presentes na carreira dos policiais rodoviários federais, pode-se afirmar que o intuito foi alcançado. Predominou-se como um dos principais fatores motivacionais o relacionamento entre colegas, ou seja, valorizam muito o coleguismo, pois este fator determina um ambiente de trabalho agradável, resultando em qualidade nas atividades executadas. Contudo, outros fatores também predominaram, como salário e remuneração, embora este ultimamente tenha sofrido algumas modificações como, por exemplo, corte do adicional noturno. As vantagens não pecuniárias também estão presentes como fatores motivacionais, como a escala de serviço, visto que os possibilitam ter qualidade de vida, isto é, a escala de serviço flexível propicia ter tempo para a família, lazer, estudos etc, e a estabilidade, outro fator acentuado, é uma garantia de futuro seguro.

Também constatou-se que a Coordenação Geral de Recursos Humanos e a Seção de Recursos Humanos têm pouca participação em práticas de Gestão de Pessoas e, quando o fazem, é algo superficial que os próprios policiais nem percebem, pois a maioria não tem conhecimento de alguma prática de Gestão de Pessoas, nem do próprio RH da PRF e tampouco por parte da administração pública. Essa participação inativa pode ser um dos motivos geradores da desmotivação entre os entrevistados, uma vez que mais da metade afirmou que a motivação está baixa, pior do que quando ingressaram na carreira. Cabe ressaltar que a participação inativa do RH não é o único motivo que resulta na desmotivação, há outros motivos conforme os relatos, como: falta de estrutura, corte de benefícios e promessas não cumpridas.

No que condiz ao perfil dos entrevistados, é legítimo afirmar que é uma equipe jovem, pois a média de idade é de 37 anos, sendo que o entrevistado mais novo tem 30 anos e o mais velho 49 anos de idade. Isso permite observar que não há grandes diferenças entre gerações, ou seja, o conflito de gerações não é o motivo para possíveis atritos. O nível de escolaridade é praticamente igual, $82 \%$ dos policiais têm ensino superior completo, isso corresponde a nove entrevistados. No que tange a tempo de cargo, predominou-se que 64\% têm nove anos de efetivo exercício. Ressalta-se que o ambiente é predominantemente masculino, dos 11 entrevistados a equipe conta com apenas uma mulher.

Apesar de os resultados não poderem ser generalizados, considerando-se que foi feito um estudo de caso em apenas uma unidade da PRF, pode-se afirmar que este estudo é válido. Mesmo com essa restrição, acredita-se que esta pesquisa trouxe 
contribuições teóricas e práticas quanto à motivação dos Policias Rodoviários Federais. Identificaram-se os fatores que os motivam e principalmente as causas que geram desmotivação, considerando que a maioria destas causas não se restringe apenas aos entrevistados e sim a todos que fazem parte da carreira, um exemplo é o corte de alguns benefícios financeiros.

A limitação deste trabalho foi de uma amostra não ampla, ou seja, foi de cunho qualitativo e aconselha-se, para pesquisas futuras, uma amostra mais ampla, isto é, de uma maneira que a pesquisa seja válida de forma probabilística. Recomenda-se a continuidade desse tema, posto que não foi muito discutido na área de administração pública. Conforme percebido no decorrer do trabalho e nos depoimentos dos entrevistados, averiguou-se que a esfera pública necessita de uma Gestão de Pessoas, ou seja, de um olhar mais atencioso para com os servidores.

\section{REFERÊNCIAS}

BARROS, A. J. S.; LEHFELD, N. A. S. Fundamentos da Metodologia Científica. 3. ed. São Paulo: Pearson Prentice Hall, 2007.

BERGuE, S. T. Gestão de Pessoas em Organizações Públicas. 2.ed. Caxias do Sul: Educs, 2007.

BRASIL. Constituição da República Federativa do Brasil de 1988. Disponível em $<$ http://www.planalto.gov.br/ccivil_03/constituicao/constituicao.htm> Acesso em: 10 abr. 2014.

. Lei. $\mathbf{n}^{0} 8.112$ de11 de Dezembro de 1990. Disponível em:

<http://www.planalto.gov.br/ccivil_03/leis/18112cons.htm> Acesso em: 09 abr.2014.

Lei no 9.503 de 23 de setembro de 1997. Disponível em:

<http://www.planalto.gov.br/ccivil_03/leis/19503.htm> Acesso em: 05 abr. 2014.

CERVO, A.; BERVIAN, P.; SILVA, R. Metodologia Científica. 6. ed. São Paulo: Pearson,2006.

CHIAVENATO, I. Administração dos novos tempos. 2ed. Rio de Janeiro: Person, 2010.

FALLER, B. C. Motivação no Serviço Público: Um Estudo de caso da Secretaria de Administração da Prefeitura Municipal de santa Cruz do Sul. Porto Alegre: UFRGS, 2004. Dissertação (Mestrado em Administração), Escola de Administração, Universidade Federal do Rio Grande do Sul, 2004.

FIORELLI, O. J. Psicologia para Administradores. 3.ed. São Paulo: Atlas, 2003. 
JR., J.F. H. et al. Fundamentos de métodos de pesquisa em Administração. 1 ed. Porto Alegre: Bookman, 2005.

KRUMM, D. Psicologia do Trabalho: Uma introdução à psicologia industrial organizacional. Rio de Janeiro: LCT, 2005.

LORENZ, K. Os fundamentos da etologia. São Paulo: Editora da Universidade Estadual Paulista, 1995.

MALHOTRA, N. K. Pesquisa de Marketing: Uma orientação aplicada. 6 ed. Porto Alegre: Bookman, 2010.

MARCONI, M. de A.; LAKATOS, E. M;. Técnicas de pesquisa: planejamento e execução de pesquisas, amostragens e técnicas de pesquisa, elaboração, análise e interpretação de dados. 7 ed. São Paulo: Atlas, 2008.

MAXIMIANO, A. C. A;. Administração para Empreendedores: fundamentos da criação e da gestão de novos negócios. São Paulo: Pearson Prentice Hall, 2006.

MAZZA. A.. Manual de Direito Administrativo. 3 ed. São Paulo: Saraiva, 2013.

MENEGON, L. F. Comportamento Organizacional. São Paulo: Pearson Education do Brasil, 2012.

ROBBINS, S. P. Fundamentos do Comportamento Organizacional. 12. ed. São Paulo: Pearson Prentice Hall, 2008. Hall, 2005.

Comportamento Organizacional. 11. ed. São Paulo: Pearson Prentice

\section{2 . \\ Comportamento Organizacional. 9. ed. São Paulo: Pearson Prentice Hall,}

SALGADO, L. Motivação no Trabalho. Rio de Janeiro: Qualitymark, 2005.

SANTANA, T. P. Motivação no serviço público municipal: Um estudo de caso feito à luz da Teoria Frederick Herzberg. Salvador: UFBA, 2011.Trabalho de Conclusão de Curso (Graduação em Administração). Escola de Administração, Universidade Federal da Bahia, 2011.

VERGARA, S. C;. Gestão de Pessoas. 4. ed. São Paulo: Atlas, 1999.

VIANNA, M. A. F. Trabalhar, para quê? 2.ed.São Paulo: Gente, 1997. 